\title{
Compreendendo a Psicomotricidade
}

\author{
Cybele Lima Batista Arraes' ${ }^{\text {; Eva Lopes de Macedo Cordeiro }}{ }^{2}$; \\ Josecleide Lopes de Macedo ; Gresciliane de Araújo Soares ${ }^{3}$
}

\begin{abstract}
Resumo: Este trabalho visa discutir sobre a importância da educação psicomotora, dos movimentos corporais na educação humana, em todas as fases do desenvolvimento infantil. Os elementos psicomotores são vivenciados, dentro de contextos histórico-culturais e afetivos significativos, desta forma para ter coordenação motora fina, a criança precisa desenvolver a motricidade ampla, organizar seu corpo, ter experiências motoras que estruturem sua imagem e seu esquema corporal. Para alcançar os objetivos propostos deste trabalho, utilizamos como base teórica o trabalho de: Costa (2002), Fonseca (1996), Paim (1989), entre outros. A pesquisa será de caráter bibliográfico e objetiva obter subsídios teóricos para oportunizar e contribuir como o processo da educação psicomotora, além de ser um estudo de suma relevância para os educadores do ensino infantil. De fato, fazer entender que o corpo é um só, já que tradicionalmente as escolas só visam o desenvolvimento intelectual. Enfatiza que a educação psicomotora é entendida como uma metodologia de ensino que instrumentaliza o movimento da criança, porém, esse estudo ressalta: a inteligência, a afetividade (sentimentos e emoção), o social (relações pessoais) e o motor (os movimentos em geral). Nesse sentido, é de suma importância a atividade lúdica, realizada através de atividades psicomotoras, de modo a colaborar para o desenvolvimento integral da criança, e para que ela possa sedimentar bem esses "pré-requisitos", fundamentais também para a sua vida escolar.
\end{abstract}

Palavras chave: Educação, Psicomotora, Desenvolvimento

\section{Understanding Psychomotricity}

\begin{abstract}
This work aims at discussing the importance of psychomotor education, of body movements in human education, in all phases of child development. The psychomotor elements are experienced within significant historical-cultural and affective contexts, so in order to have fine motor coordination, the child needs to develop broad motor skills, organize his body, have motor experiences that structure his image and his corporal scheme. In order to reach the proposed objectives of this work, we use as theoretical basis the work of: Costa (2002), Fonseca (1996), Pain (1989), among others. The research will be of a bibliographic character and aim to obtain theoretical subsidies to provide and contribute as the process of psychomotor education, besides being a study of great relevance for the educators of the infantile education. In fact, make it understood that the body is one, since traditionally schools only aim at intellectual development. Emphasizes that psychomotor education is understood as a teaching methodology that instrumentalizes the child's movement, but this study emphasizes: intelligence, affectivity (feelings and emotion), social (personal relationships) and motor (movements in general ). In this sense, it is of utmost importance the play activity, carried out through psychomotor activities, in order to collaborate for the integral development of the child, and so that it can well sediment those prerequisites, fundamental also for his school life
\end{abstract}

Keywords : Psychomotor, Education, Development

\footnotetext{
${ }^{1}$ Universidade Tecnológica Intercontinental. Contato: cybarraes@ hotmail.com;

2 Professor - Coordenador Pedagógico nas Escolas Anizio R.Coelho; Santa Helena e Manoel Lopes de Macedo. Araripina, Pernambuco, Brasil;

${ }^{3}$ Mestrado Em Ciências da Educação Pelo Universsidad Hispano Guaraní, Paraguai. Professora da Escola Municipal Manoel Lopes de Macedo , Brasil;

${ }^{4}$ Graduada em Geografia pela Faculdade de Formação de Professores de Serra Talhada(FAFORPST),especialista em Geografia e Meio Ambiente pela Universidade Regional do Cariri ( URCA) e PRÁTICA DOCENTE DO ENSINO SUPERIOR pela Faculdade Integrada de Patos (FIP). Mestrado em andamento em Ciências da Educação pela ANNE SULLIVAN UNIVERSITY. Atualmente, professora do CENTRO EDUCACIONAL DO CARIRI e na E.E.I.F.M.COLÉGIO O AUTÊNTICO. Contato: soaresmoura2015@gmail.com.
} 


\section{Introdução}

Os movimentos do corpo iniciam desde o nascimento, é o começo do desenvolvimento infantil o qual não apresenta significados ainda inscritos, mas aos poucos, este corpo em movimento transforma-se em expressão de desejo e, posteriormente, em linguagem. Logo a criança se torna capaz de reproduzir situações reais, fazendo imitações que se transforma em faz-de-conta. Assim a, a criança consegue separar o objeto de seu significado, falar daquilo que está ausente e representar corporalmente. Este processo nada mais é do que a vivência dos elementos psicomotores dentro de contextos histórico-culturais e afetivos significativos. E isso, é que garante a aprendizagem de conceitos formais aliados a aprendizagem de conceitos do cotidiano: construir textos, contar uma história, dar um recado, fazer compras, varrer a casa, utilizar as operações matemáticas para contar quantas pessoas vieram, quantas faltaram, ir ao banco, etc.

Além disso, para chegar a uma coordenação motora fina necessária à construção da escrita, a criança precisa desenvolver a motricidade ampla, organizar seu corpo, ter experiências motoras que estruturem sua imagem e seu esquema corporal. Portanto, a psiscopedagogia e a psicomotricidade estão intimamente ligadas. Antes de aprender a matemática, o português, os ensinamentos formais, o corpo tem que estar organizado, com todos os elementos psicomotores estruturados. Uma criança que não consegue organizar seu corpo no tempo e no espaço, não conseguirá sentar-se numa cadeira, concentrar-se, segurar num lápis com firmeza e reproduzir num papel o que elaborou em pensamento.

\section{Uma Visão Histórica}

A psicomotricidade é uma ciência que possui uma importância cada vez maior no desenvolvimento global do indivíduo em todas as fases, principalmente por estar articulada com outros campos científicos como a Neurologia, a Psicologia e Pedagogia. Isso acontece porque a Psicomotricidade se preocupando com a relação entre o homem e o seu corpo, considerando não só aspecto psicomotores, mas aspectos cognitivos e sócio-afetivos que constituem o sujeito. Como se refere Costa, 


\begin{abstract}
A Psicomotricidade baseia-se em uma concepção unificada da pessoa, que inclui as interações cognitivas, sensoriomotoras e psíquicas na compreensão das capacidades de ser e de expressar-se, a partir do movimento, em um contexto psicossocial. Ela se constitui por um conjunto de conhecimentos psicológicos, fisiológicos, antropológicos e relacionais que permitem, utilizando o corpo como mediador, abordar o ato motor humano com o intento de favorecer a integração deste sujeito consigo e com o mundo dos objetos e outros sujeitos (Costa,2002).
\end{abstract}

Em 1982 a Sociedade Brasileira de Terapia Psicomotora, atual Sociedade Brasileira de Psicomotricidade, propõe uma definição bastante abrangente do que vem a ser psicomotricidade. Psicomotricidade é uma ciência que tem por objetivo o estudo do homem, através do seu corpo em movimento, nas relações com seu mundo interno e externo. Conforme afirmação da Associação Brasileira de Psicomotricidade.

Psicomotricidade é a ciência que tem como objeto de estudo o homem através do seu corpo em movimento e em relação ao seu mundo interno e externo. Está relacionada ao processo de maturação, onde o corpo é a origem das aquisições cognitivas, afetivas e orgânicas. É sustentada por três conhecimentos básicos: o movimento, o intelecto e o afeto. (Associação Brasileira de psicomotricidade)

O termo "psicomotricidade" aparece, pela primeira vez, no discurso médico, mais especificamente, no campo da Neurologia, quando, no século XIX houve uma preocupação em identificar e nomear as áreas específicas do córtex cerebral segundo as funções desempenhadas por cada uma delas. E foi no século XX que ela passou a desenvolver-se como uma prática independente e, aos poucos, transforma-se em ciência. Até conseguir ter o espaço que ocupa hoje, a psicomotricidade começou a ser praticada no momento em que o corpo deixou de ser visto apenas como um pedaço de carne, para ser algo indissociável do sujeito.

No século XVII, René Descartes ainda propunha esta dicotomia estre o corpo e alma, mas já fazia colocações de que o corpo é tão unido à pessoa que ambos chegam a "misturarse".

No século XIX constatou-se que existem disfunções graves evidenciadas no corpo sem que o cérebro tenha nenhuma lesão. Segundo Levin, é esta "necessidade médica de encontrar uma área que explique os fenômenos clínicos que nomeia pela primeira vez a palavra psicomotricidade, no ano de 1870 " 
Em 1909, Dupré define a síndrome da debilidade motora, através das relações entre o corpo e inteligência, dando partida para o estudo dos transtornos psicomotores, patologias não relacionadas a nenhum indício neurológico estudadas pela psicomotricidade.

Henry Wallon, em 1925 começou a relacionar a motricidade com a emoção, explicando que chamou de "diálogo tônico-emocional". E com essa teoria, temos o fim do dualismo cartesiano que separa o corpo do desenvolvimento intelectual e emocional do indivíduo.

A prática mais especificamente psicomotora começou em 1995, com Eduard Guilmain, que elaborou protocolos de exames para medir e diagnosticar transtornos.

Em 1948 Ajuriaguerra redefiniu o conceito de debilidade motora e delimitou com clareza os transtornos psicomotores no seu Manual de Psiquiatria Infantil. Este é um dos autores que até hoje continua sendo citado nos trabalhos relacionados ao desenvolvimento infantil.

Outros pesquisadores importantes da área: Jean Lê Bouch, Andre Lapierre, Bernard Auconturier, Aleksander Luria, P. Vayer, Jean Berges, Jean-claude Coste e Vitor Fonseca

\section{Dificuldades de Aprendizagem}

Muitas das dificuldades escolares não se apresentam em função do nível da turma a que as crianças chegaram, em relação à elementos básicos ou "Pré-requisitos ", condições mínimas necessárias para uma boa aprendizagem , que constituem a estrutura da educação psicomotora. Nesse sentido, é de suma importância a atividade lúdica, realizada através de atividades psicomotoras, no sentido de colaborar para o desenvolvimento integral da criança, e para que ela possa sedimentar bem esses "pré-requisitos", fundamentais também para a sua vida escolar.

Freire diz: "causa mais preocupação, na escola da primeira infância, ver criança que não sabem saltar que crianças com dificuldades para ler ou escrever"(Freire, 1989,p76)

Descobri as habilidades de saltar correr, lançar, etc. é importante para o desenvolvimento pleno do aluno, como um organismo integrado, levando-se em conta que tais habilidades são consideradas como formas de expressão de um ser humano. 
A escola não deve se preocupar em ensinar habilidades apenas para que o aluno saiba executá-las bem ou para facilitar a execução das tarefas escolares, mas sim direcionar a aprendizagem para a formação integral do aluno. Considerar o gesto ou a linguagem corporal como forma de expressão do ser humano é um caminho para reconhecer a importância da atividade corporal no processo ensino-aprendizagem.

Antes dos homens se comunicarem através de símbolos, a expressão corporal se constituiu na primeira forma de linguagem. Coste, ressalta que, "O corpo é de fato, um lugar original de significações específicas e, por ser parte integrante de nosso universo de símbolos, é produto e gerador, ao mesmo tempo, de signos".

Fonseca afirma que, as atividades desenvolvidas na escola como a leitura, o ditado, a redação, a cópia, o cálculo, o grafismo, a música e enfim, os movimentos, estão ligadas à evolução das possibilidades motoras e as dificuldades escolares estão portanto , diretamente relacionadas aos aspectos psicomotores.

A Psicomotricidade centra-se na importância da educação psicomotora como base para as aprendizagens escolares, no sentido de reforçar o caráter preventivo e a importância de sua existência nas instituições escolares, visando o desenvolvimento integral dos alunos. Fonseca (1996, p. 142)

Desta feita Fonseca ressalta o caráter preventivo da psicomotricidade, a primeira necessidade seria, portanto: [...] alfabetizar a linguagem do corpo e só então caminhar para as aprendizagens triviais que não são mais que investimentos perceptivos- motores ligados por coordenadas espaço temporais e correlacionados por melodias rítmicas de integração e respostas. É através do movimento (ação) que a criança integra os dados sensitivo-sensoriais que lhe permitem adquirir a noção dos eu corpo e a determinação de sua lateralidade.

\section{Transtornos Psicomotores}

Os principais transtornos são:

1. Instabilidade psicomotora - neste transtorno a criança não consegue começar e terminar a brincadeira e é assim com todas as suas produções corporais. Há uma dificuldade em inibir seus movimentos, provocando ações explosivas e agressivas. 
São crianças agitadas, ansiosas e inquietas, pois possuem uma grande necessidade em movimentar-se. Encaixam-se nos diagnósticos de hiperatividade, precisando, em alguns casos com perturbações severas no sono e na atenção, de medicamentos como anfetamina e psicotônicos. As crianças com este transtorno podem ter uma grande tensão muscular e patologias severas caracterizando uma instabilidade tensional, ou serem hipotônicas, elásticas e bastante flexíveis, o que chamamos de estado de deiscência. Em ambos os casos, a causa do transtorno é a falta de limite, a ausência de corte simbólico.

2. Inibição psicomotora- neste transtorno a criança não usa seu corpo para relacionar-se com o mundo ou com os outros. É o oposto da instabilidade, pois também há uma falta de limite, mas esta falta barra o agir da criança. Ela mostra-se então cansada, demonstrando pouca expressão facial e corporal. Seu aspecto é de extrema fragilidade e debilidade e é nele que se reconhece e é reconhecida. São crianças "quietinhas demais" Segundo Levin, "a criança inibida diferentemente da instável, possui outra estratégia para não se separa do outro, ser o objeto de seus pais, os quais usam expressar-se do seguinte modo: é como se não tivesse, nem dá para ouvir, não briga com ninguém, passa inadivertidamente"

3. Debilidade - é caracterizada pela presença de paratonias e sincinesias. A paratonia é a persistência de uma rigidez muscular caracterizada por uma inadequada incontinência das reações tônicas. Pode aparecer nos quatro membros ou apenas em dois. Há uma instabilidade na posição estática ou quando a criança caminha ou corre devido à rigidez. A sincinesia é caracterizada pela ação de músculos que não atua, em determinado movimento. Um exemplo desta situação é a criança fechar também a mão esquerda quando pega um objeto com a direita. Isto a impede de realizar atos coordenados e com ritmo devido a sua descontinuidade nos gestos e imprecisão dos movimentos, Podem aparecer ainda outros sintomas como tremores na língua, lábios, pálpebras e dedos quando estes são solicitados para a execução de um determinado movimento. A afetividade e a intelectualidade também podem estar comprometidas. A criança geralmente demonstra uma certa apatia e tem sonolência maior que as outras crianças. mantém por muitos anos a enurese 
noturna, e, ás vezes a diurna, podendo apresentar também a encoprese . A linguagem é atrasada e a atenção, prejudicada.

4. Dispraxia - dificuldade de associar movimentos para realizar uma tarefa. Há um transtorno espacial (dificuldades de lateralizar, de nomear objetos, espelhamentos de letras, assimetria nos movimentos - todos estes aparecendo persistentemente).Há também um fracasso nos jogos. Há um desvio no desenvolvimento cognitivo no que diz respeito à disposição figurativas, o que impede que a criança atinja a fase de operações concretas. Há uma perturbação do esquema corporal. Quando a dispraxia é no olhar, além das perturbações perceptivas, há dificuldades posturais e de equilíbrio.

\section{Campos de Atuação}

A educação psicomotora é dirigida à atuação física Lê Boulch, na segunda metade da década de 60, já visando o desenvolvimento global do indivíduo por meio dos movimentos e, mais especificamente, evitar distúrbios de aprendizagem. Assim, a psicomotricidade atua proporcionando ambientes que atingindo suas zonas de desenvolvimento, como defende Vygotsky.

Atualmente, na psicomotricidade, existem três campos de atuação: reeducação, terapia e educação. A reeducação é o atendimento individual a ou em pequenos grupos de criança, adolescente ou adultos que apresentam sintomas de ordem psicomotora. Estes sintomas podem vir acompanhados de distúrbios mentais, orgânicos, psiquiátricos, neurológicos, relacionais e afetivos.

A terapia psicomotora é também realizada com crianças, adolescentes, ou adultos individualmente ou em pequenos grupos que apresentam grandes perturbações de ordem patológica. 


\section{A Importância do Brincar}

Brincar é um ato social que permite uma comunicação através de gestos, mesmo que não haja comunicação verbal. É no brincar que a criança tem a oportunidade de expressa o que está sentindo ou necessitando; é através das brincadeiras, do faz de conta , que a criança constroi o seu mundo imaginário situado em experiências vividas. A criança utiliza-se do brincar para construir sua aprendizagem, porque é na brincadeira que ela explora situações usando a imaginação e libera seu eu criativo, realizando seus desejos mais íntimos.

Fonseca, argumenta que no jogo a criança tem a oportunidade de estruturar o seu esquema corporal, a sua relação com o espaço e o tempo, a ampliar a utilização do perceptivo motor e ainda estampar sua afetividade, proporcionando o desencadear se suas emoções.

É brincando que a criança aprende a trabalhar suas frustrações na medida em que perde ou ganhar. Esse fator torna-se inerente ao crescimento e fortalece emocionalmente o indivíduo e as relações com o outro. Neste caso ganham importância vital, pois a criança necessita compartilhar momentos coletivos para satisfazer à vontade de jogar e aprender a conviver no grupo.

Fonseca afirma a importância do jogo na fase infantil como: por ser um fator de desenvolvimento orgânico e funcional, porque é através do movimento desencadeado no jogo que acontece a mielinização dos nervos e as conexões que interligam estas comunicações multiplicam-se favorecendo o enriquecimento das estruturas cerebrais e por ser é um fator de libertação e de formação, que não pode faltar à criança em desenvolvimento, dado que além da satisfação catártica que permite, implica também uma subestimação dos instintos e tendências anti-sociais.

Desta forma é na brincadeira que é possível trabalhar a representação simbólica a construção de forma branda e aceitável na colocação de limites e combinações que darão subsídios à socialização e à criação das regras coletivas.

Enfim, o brincar é amaneira pela qual a criança busca subsídios lúdicos para desenvolver-se. E o mais importante de tudo isso é que, por meio do brincar, o professor assume um papel fundamental neste processo, pois é ele que arma, de maneira planejada e não casual, as cenas mais pertinentes para que esse desenvolvimento ocorra. É ele que fará com 
que o sujeito não se fragmenta, pois ele se oferece como elo de todos os aspectos que constituem um indivíduo: os aspectos psicomotores, cognitivos e sócio-afetivos.

\section{Educação Física}

A educação física, como ação psicomotora e por meio da educação psicomotora, incentiva a prática do movimento em todo a transcurso de existência dos er humano. Tal Concepção fundamenta-se nos conceitos da educação permanente, como uma nova forma de evento educativo que atualmente tende a revolucionar os sistemas educacionais de todo o mundo. Ela diversifica-se em função das relações sócias, das ideias morais, das capacidades e da maneira de ser de cada um, além de seus valores; educa o movimento, ao mesmo tempo em que põem em jogo as funções da inteligência. A partir dessa posição, pode-se ver a relação intrínseca das funções motoras cognitivas e que, também pela afetividade.

No entanto vai ser apresentada uma Educação Física que busca auxiliar o trabalho da Educação Psicomotora com posicionamentos adequados para evitar algumas invasões em áreas científicas desiguais. Algum dos aspectos de maior relevância é conhecer e procurar estar sempre estabelecendo atividades de acordo com a faixa etária ou etapa de crescimento de cada menino ou menina, uma vez determinado esses fatores teremos uma criança com sua formação corporal adequada e consequentemente no futuro adultos com pouco ou nenhum déficit no aspecto psicomotor.

\section{Conclusão}

Reconhecendo a existência de outros fatores que se manifestam nas crianças , originando dificuldades de aprendizagem, tais como, dificuldade de sociabilidade e no campo afetivo/emocional , fadiga , impossibilidade físicas e dificuldades em relação à estrutura escolar, esse estudo ficou centrada na importância da educação psicomotora como base para as aprendizagens escolares, no sentido de reforçar o caráter preventivo e a importância de sua existência nas instituições escolares, visando o desenvolvimento integral dos alunos. 
Também se faz relevante, ressaltar a importância de um trabalho integrado entre professores, orientadores educacionais, coordenadores e o profissional de Educação Física, para uma avaliação criteriosa do aluno e contribuição na superação das dificuldades apresentadas.

Em virtude de situações complexas, por vezes se faz necessária a intervenção de outros profissionais, como, psicólogos e médicos, nesse processo de avaliação e superação. Deve-se ter o cuidado em não "rotular" os alunos que apresentam algumas características específicas, sob a pena de discriminá-los no grupo e dificultar ainda mais a sua superação. Uma reflexão profunda deve ser feita, periodicamente, na escola, sobre métodos e práticas pedagógicas a serem aplicadas nas diversas áreas, também relacionadas ao caráter preventivo das dificuldades de aprendizagem.

Temos de resgatar a Educação Psicomotora de uma forma ou de outra pela sua importância no desenvolvimento global da criança levando em consideração que só existe educação quando estamos sendo educado num todo. Preparando o corpo todo, não só a nossa inteligência, mas também as emoções, os sentimentos, as relações sociais, os movimentos em geral. Aprender o esquema corporal, a estruturação espaço-temporal e desenvolver as percepções diversas como olfato, tato, visão paladar e audição, dando ao corpo noção exata de como viver no ambiente coletivo, aprendendo a usar seu corpo através dos movimentos explorando cada detalhe. Cada lugar do espaço, aprenderem a utilizar o tempo e tudo em volta com seus objetivos.

Finalmente a terapia psicomotora principalmente deve estar baseada em atividades lúdicas e estimulantes. A criança evolui pedagogicamente na medida exara que entende que conhecer é bom, fazer é ótimo. A escola e a família, nesse sentido podem ser o campo fecundo, o continente às suas necessidades e aspirações.

\section{Referências}

CENTRO ESPORTIVO VIRTUAL. Disponível em: <http://cev.org.br/bibblioteca/apsicomotricidade-prevencao-das-dificuldades-aprendizagem>. Acesso em: 20.07.2017.

CÓDIGO DE ÉTICA DA ABPp Elaborado pelo Conselho Nacional do Biênio 91/92 e Reformulado pelo Conselho Nacional e Nato do Biênio 95/96 
Id on Line Revista Multidisciplinar e de Psicoloqia

Id on Line Multidisciplinary and Psycology Journal

COSTA, A. C. Psicopedagogia e psicomotricidade: Pontos de intersecção nas dificuldades de aprendizagem: Petrópolis: Vozes, 2002.

COSTE, J.A Psicomotricidade. Rio de Janeiro: Zahar, 1978.

FERNANDES, A. Inteligencia aprisionada. Porto Alegre: Artes Médicas, 1991.

FERNÁNDEZ, Alicia. A inteligência aprisionada. Porto Alegre: ArtMed, 1991.

FERNÁNDEZ, Alicia. Amulher escondida na professora. Porto Alegre: ArtMed,1994.

FONSECA,V . Psicomotricidade . São Paulo: Martins Fontes, 1996.

PAÍN, Sara. Diagnóstico e tratamento dos problemas de aprendizagem. $3^{\mathrm{a}}$ ed. Porto Alegre: Artes Médicas, 1989.

PAIN, S. A Função da ignorância - Estruturas Inconscientes do Pensamento. Vol. 1. P. Alegre: Artes Médicas, 1985.

SAMPAIO, Simaia. Manual Prático do Diagnóstico Psicopedagógico Clínico , Rio de Janeiro :Wak Ed.,2009

SAMPAIO, Simaia. Dificuldades de Aprendizagem : a psicopedagogia na relação sujeito, família e escola, Rio de Janeiro: Wak Ed.,2011

SCOZ, Beatriz. Psicopedagogia e Realidade Escolar: O problema escolar e de aprendizagem;Petropolis,RJ:Ed.Vozes,2013

\section{Como citar este artigo (Formato ABNT):}

ARRAES, Cybele L.B.; CORDEIRO, Eva, L.M.; MACEDO, Josecleide L.; SOARES, Gresciliane A. Compreendendo a Psicomotricidade. Id on Line Revista Multidisciplinar e de Psicologia, Julho de 2017, vol.11, n.36, p.284-294. ISSN: 1981-1179.

Recebido: 27.07.2017

Aceito: 29.07 .2017 